\title{
Propostas de redução da idade penal no Brasil e o Estatuto da Criança e do Adolescente
}

Aline Kelly da Silva. Faculdade Pitágoras - Unidade Maceió

Simone Maria Hüning. Universidade Federal de Alagoas

\section{Resumo}

Neste artigo discutimos como as propostas de redução da idade penal no Brasil tensionam o Estatuto da Criança e do Adolescente. A partir da genealogia e da arqueologia propostas por Michel Foucault analisamos as Propostas de Emenda Constitucional apresentadas pela Câmara de Deputados entre os anos de 1993 e 2013. Nossa análise indica que as propostas criticam o critério cronológico adotado pelo Estatuto e propõem sua substituição pelo que chamam de critério subjetivo-psicológico. Postos em oposição aos direitos sociais, os direitos civis são tomados como balizadores de uma responsabilização dos sujeitos jovens, tornando-os mais penalizáveis. Por fim, as propostas fazem uma série de críticas à ineficácia do Estatuto da Criança e do Adolescente. Essas críticas não são produzidas no sentido de ampliar a efetivação das atuais políticas, mas de instrumentar o recrudescimento punitivo a partir da desqualificação do Estatuto.

Palavras-chave: maioridade penal; Estatuto da Criança e do Adolescente; controle social.

\begin{abstract}
Proposals to reduce the age of criminal responsibility in Brazil and the Child and Adolescent Statute. This paper discusses how the proposals to reduce the age of criminal responsibility in Brazil strain the Statute of Children and Adolescents. Applying the archaeological and genealogical methods of Michel Foucault we analyze the constitutional amendment proposals presented by the country's Chamber of Deputies between 1993 and 2013. Our analysis points out that the proposals criticize the chronological criteria adopted by the Statute and propose replacing it with the so-called subjective-psychological criteria. Placed in opposition to social rights, civil rights are used as a reference to hold young subjects responsible, thereby making them more penalizable. Finally, the proposals critique the ineffectiveness of the Statute of Children and Adolescents. These critiques are not the result of attempts to expand the efficacy of current policies, but rather to implement a punitive upsurge starting with the disqualification of the Statute.
\end{abstract}

Keywords: age of criminal responsibility; Child and Adolescent Statute; social control.

\section{Resumen}

Propuestas de reducción de la edad penal en Brasil y el Estatuto del Niño y del Adolescente. En este artículo discutimos cómo las propuestas de reducción de la edad penal en Brasil tensionan el Estatuto del Niño y del Adolescente. A partir de la arqueología y de la genealogía propuestas por Michel Foucault analizamos las Propuestas de Enmienda a la Constitución presentadas por la Cámara de Diputados entre los años 1993 y 2013. Nuestro análisis indica que las propuestas critican el criterio cronológico adoptado por el Estatuto y proponen su sustitución por lo que califican de criterio subjetivo/psicológico. Puestos en oposición a los derechos sociales, los derechos civiles son utilizados como referenciales de una responsabilización de los sujetos jóvenes, volviéndolos más penalizables. Finalmente, las propuestas hacen críticas a la ineficacia del Estatuto del Niño y del Adolescente. Estas críticas no son producidas en el sentido de ampliar la efectuación de las actuales políticas, pero de instrumentar el recrudecimiento punitivo a partir de la descalificación del Estatuto.

Palabras clave: mayoría de edad penal; Estatuto del Niño y del Adolescente; control social. 
Em agosto de 2014, publicou-se uma matéria na internet intitulada "Na prática, SP já reduziu a maioridade penal, diz antropólogo" (Ponte, 2014). O pesquisador Fábio Mallart, entrevistado nessa matéria, realizou uma pesquisa etnográfica na Fundação Casa de São Paulo, participando da rotina da instituição entre 2004 e 2009 e constatou que, apesar de o Estatuto da Criança e do Adolescente (ECA) prever que as medidas socioeducativas tenham caráter pedagógico, a realidade institucional por ele pesquisada evidencia uma lógica punitiva e carcerária direcionada aos jovens atendidos (Mallart, 2014). Estudos anteriores também apontaram situação semelhante, mencionando que os estabelecimentos socioeducativos são atravessados por uma cultura da cadeia e do castigo (Augusto, 2013; Espíndula \& Santos, 2004; Yokoy \& Oliveira, 2008).

Ao fazermos referência ao estudo em que Mallart (2014) aponta um alinhamento entre sistema socioeducativo e prisional, atentamos para a importância de discutir o Estatuto da Criança e do Adolescente (ECA), especialmente tendo em vista a atualidade do debate sobre a redução da idade penal e a garantia de direitos para a infância e a juventude pautada nos princípios do ECA. Este artigo objetiva discutir os tensionamentos provocados ao Estatuto da Criança e do Adolescente pelas propostas de redução da idade penal apresentadas na Câmara de Deputados brasileira.

A construção de políticas públicas para a infância e a juventude no Brasil remonta ao final do século XIX quando, de acordo com Rizzini (2011), a criança passou a ser entendida como uma questão social e, portanto, objeto de interesse do Estado e não somente da família ou da Igreja. A partir da idealização do projeto de construção de um Brasil civilizado, à semelhança dos países europeus, passou-se a pensar na criança como 'futuro da nação' e surgiu, então, a necessidade de tomá-la como um dos principais meios de intervenção do Estado no tecido social.

Ao longo do século XIX, desenvolveu-se o que Rizzini (2011) chamou de aliança jurídico-assistencial, a partir da qual a proteção à infância passa a ser sinônimo de contenção da desordem familiar e formulam-se leis específicas no sentido de garantir a tutela do Estado sobre as famílias. Após a proclamação da República, começaram a tramitar as primeiras leis na Câmara de Deputados brasileira no sentido de garantir a tutela do Estado sobre a infância, especialmente quando envolvida com a 'delinquência', e constroem-se dispositivos de intervenção calcados em procedimentos judiciais. Ainda de acordo com Rizzini (2011), nas primeiras décadas do século XX apresentaram-se diversos projetos de lei no legislativo federal brasileiro, tomando os 'menores' como alvo de classificação e tutela. Em 1927, passa a vigorar no país o Código de Menores, tendo como pressuposto a contenção dos assim chamados 'menores delinquentes' ${ }^{1}$ ou em potencial de o ser. O segundo Código de Menores, instaurado no Brasil em 1979, constituiu-se como uma tentativa de conciliar o modelo proposto pelo Código de 1927 com algumas críticas contra esse modelo repressivo das ações destinadas à infância. Deixa-se de apreender a infância pobre como perigosa, mas passa-se a investir nesses sujeitos concebendo-os como abandonados e carentes em suas condições materiais e familiares.

Na década de 1980, já no contexto de abertura democrática do Brasil, diversos movimentos sociais, tais como o Movimento Nacional de Meninos e Meninas de Rua e a Pastoral da Criança, intensificam as críticas às políticas estatais e aos modos de conceber a infância a partir do Código de Menores de 1979. Forma-se nesse período o Fórum de Direitos da Criança e do Adolescente (Fórum DCA), objetivando mudanças voltadas às políticas infanto-juvenis na Constituição Brasileira (Santos, 2009) e elabora-se, então, o ECA, a partir das legislações internacionais de proteção a crianças e adolescentes, pautado na Doutrina da Proteção Integral e concebendo crianças e adolescentes como sujeitos de direitos, em condição peculiar de desenvolvimento (Lei $n^{\circ}$ 8.069/90).

É importante atentarmos para o fato de que a produção de políticas destinadas ao segmento infanto-juvenil esteve ligada historicamente à construção de modos de governo sobre essa população bem como de estratégias de intervenção sobre as famílias, aliadas a certos interesses políticos e econômicos. É nesse contexto de embates políticos e da articulação de diferentes saberes que tomam como alvo a infância e a juventude que o ECA constitui-se como marco legislativo que respalda a produção de políticas públicas. Fruto, portanto, de um contexto histórico específico de abertura democrática do país e de lutas e discussões coletivas travadas nesse período. Por ser o principal marco legislativo que vigora atualmente na garantia de direitos para crianças e adolescentes, é fundamental, diante da retomada da discussão sobre a redução da idade penal no Brasil, analisarmos de que modo esse debate coloca em discussão o próprio ECA.

\section{Método}

As teorizações de Michel Foucault nortearam a produção e a análise dos dados. Adotamos a arqueogenealogia foucaultiana como método de pesquisa que possibilita problematizarmos o presente, considerando que analisar o presente é também desestabilizá-lo, evidenciar as contingências e os percursos sinuosos pelos quais nos tornamos o que somos. Compreendemos a arqueogenealogia como um entrelaçamento da 
arqueologia com a genealogia, por considerarmos a indissociabilidade desses métodos nas interrogações feitas aos materiais de análise e na condução da pesquisa.

A arqueologia proposta por Michel Foucault se ocupa da episteme dos saberes, isto é, volta-se à análise de suas condições históricas de possibilidade. Preocupa-se, portanto, em analisar as camadas discursivas e as relações colocadas em funcionamento por determinados enunciados. Foucault propõe uma análise do discurso que considera as correlações entre enunciados, mais do que uma mera descrição de suas regras, e as condições pelas quais alguns enunciados tornaram-se possíveis em lugar de outros (Castro, 2009).

A genealogia, por sua vez, pode ser entendida como uma ampliação dos domínios de investigação de Foucault no sentido de passar a questionar os efeitos de poder na constituição de práticas e saberes que adquirem status de verdade. Trata-se de um método de investigação que articula a análise das emergências e proveniências históricas. A noção de emergência opõe-se à de origem, porque trata o ponto de surgimento dos acontecimentos como condições múltiplas de possibilidade e não como uma causa primeira ou uma origem linear. Já a proveniência opõe-se à noção de semelhança, ao buscar as marcas singulares que se entrecruzam em um emaranhado de acontecimentos e marcam os corpos bem como possíveis descontinuidades históricas dos acontecimentos (Foucault, 1979).

Ao caracterizarmos nossa pesquisa como arqueogenealógica, interrogamos os documentos analisados com as seguintes questões: Quais são os discursos produzidos sobre o ECA? De que modo eles tensionam as práticas direcionadas a crianças e adolescentes, a partir do Estatuto?

\section{Materiais de Análise}

Tomamos como materiais de análise as Propostas de Emenda à Constituição apresentadas pelos deputados brasileiros no Congresso Nacional, no período de 1993 a 2013. Uma Proposta de Emenda Constitucional (PEC) é, como o próprio nome sugere, um emendo que altera a Constituição Federal. De acordo com Santana (1993), as emendas à Constituição possuem um alcance mais restrito do que as revisões, apresentando modificações parciais, pontuais ou fragmentárias de um texto constitucional. Um detalhe significativo é que as emendas não se inserem no texto constitucional, mas registram-se ao lado ou abaixo da redação original do texto constitucional que passa a ser modificado.

Na Câmara dos Deputados, uma PEC passa primeiramente pela Comissão de Constituição e Justiça e de Cidadania (CCJC). Se houver admissibilidade, ela é enviada à Comissão Especial para análise de conteúdo. Caso haja admissibilidade, nomeia-se um relator e envia-se a proposta para votação no Plenário da Câmara. A estrutura de uma PEC geralmente é composta de: número da PEC, identificação do artigo original a ser alterado, redação da emenda proposta para o artigo, texto de justificação que fundamenta a alteração proposta, nomes e assinaturas dos proponentes e, por fim, assinaturas dos legisladores favoráveis à proposição. A análise empreendida para este trabalho voltou-se aos textos de justificação das PECs.

Apesar de a primeira PEC que propõe diminuição da idade penal ser a PEC 14/1989, de autoria do então deputado Telmo Kirst (PDS-RS), ela foi arquivada. Desde 1993 até o período de nossa última busca em 2013, 37 PECs propunham alteração da idade penal somente na Câmara de Deputados, além das propostas apresentadas pelo Senado Federal. Em 1993 foi apresentada a PEC 171/1993, à qual as propostas posteriores que versam sobre a alteração do artigo 228 da Constituição Federal estão apensadas, isto é, tramitam em conjunto com ela. Como a PEC 14/1989 não possui texto disponibilizado na íntegra por ter sido arquivada, nossa análise englobou as propostas apresentadas desde 1993 até 2013, ano em que iniciamos a pesquisa, abarcando todos os documentos produzidos na Câmara durante as duas décadas. Acessamos os textos completos de todas as propostas através do site da Câmara dos Deputados, alguns contidos nos Diários da Câmara dos Deputados e outros de modo avulso. Das trinta e sete propostas, sete não estavam disponibilizadas online. Entramos em contato com o serviço Fale Conosco, através do próprio site, e, após o recebimento via e-mail das demais propostas, chegamos ao corpus de análise da pesquisa.

\section{Procedimentos de Análise}

Com base em uma leitura na íntegra do total de 37 PECs obtidas, construímos três analisadore ${ }^{2}$ de pesquisa, a saber: tecnologias de informação e meios de comunicação de massa atrelados ao desenvolvimento psíquico; racionalidade punitiva; e, por fim, tensionamentos ao Estatuto da Criança e do Adolescente. A construção dos analisadores deu-se a posteriori, a partir da leitura dos materiais e buscando identificar os regimes de verdade produzidos aí. No escopo deste artigo, discutimos somente o terceiro analisador, que nomeamos de tensionamentos ao Estatuto da Criança e do Adolescente (ECA), uma vez que as limitações de publicação como artigo científico inviabilizariam desenvolver a articulação de todos os analisadores neste trabalho. Ressaltamos ainda que os analisadores que não fazem parte da discussão aqui desenvolvida estão postos em debate em outros trabalhos, como, por exemplo, A. K. Silva e Hüning (2015).

Como se trata de um recorte de pesquisa mais ampla, é necessário explicitar que os materiais 
abordados aqui são apenas as PECs cujos discursos enunciam questões relacionados ao ECA, o que constitui um conjunto de dez documentos dentre o conjunto dos 37 que constituíram a pesquisa. Organizamos a discussão dos dados com base na produção de três categorias de análise a respeito do analisador tensionamentos ao Estatuto da Criança e do Adolescente: 1) critério subjetivo-psicológico, 2) direitos civis versus direitos sociais e 3) ineficácia das práticas pautadas no ECA. As categorias foram elaboradas a partir dos principais temas e discursos identificados nos documentos com relação ao ECA. Ancoramos nossa discussão na análise foucaultiana do discurso (Foucault, 1969/2012a; Foucault, 1970/2012b) e em alguns operadores teórico-conceituais propostos por Michel Foucault, tais como saber-poder, governamentalidade e subjetivação. Tais ferramentas possibilitam debruçarmo-nos sobre as relações de força que os discursos põem em funcionamento, interrogando as implicações políticas e os efeitos sobre certas práticas e saberes. Interessa-nos o estatuto de verdade dos discursos na articulação entre saber e poder, a partir de um determinado momento histórico, e os efeitos sobre os modos de governar populações.

\section{Resultados e discussão}

Há uma série de desqualificações dos princípios e das práticas operados a partir do ECA, sobretudo a partir da década de 2000 , nas propostas analisadas, conforme podemos observar na Tabela 1, a seguir.

A partir da concepção de que as medidas socioeducativas são brandas, não punem suficientemente e, ao não punirem com o rigor devido, acabam acobertando e até mesmo incentivando os jovens a permanecerem na prática infracional, novos elementos vão sendo agregados a essas críticas. Conforme apontamos anteriormente, estruturamos nossa discussão em três eixos de análise: critério subjetivo-psicológico, direitos civis versus direitos sociais e interrogações sobre a eficácia das práticas a partir do ECA.

Tabela 1. Tensionamentos ao ECA

\begin{tabular}{|c|c|}
\hline Número da PEC & Excertos relacionados ao analisador 3 \\
\hline PEC 386/1996 & $\begin{array}{l}\text { Ao optar pela irresponsabilização criminal de jovens até os dezoito anos, o Legislador brasileiro desconheceu a realidade biológica, social } \\
\text { e jurídica que marca a ascensão dos adolescentes à pauta dos direitos e das obrigações inerentes à cidadania. } \\
\text { Afigura-se, pois, nada mais que ficção legal a situação de irresponsabilização penal dos menores infratores (...) [grifo nosso]. } \\
\text { Não é possível que a aparente ou real fragilidade física de menores de } 18 \text { anos sirva lamentavelmente como biombo para ocultar a carga } \\
\text { de crimina1idade e de violência de que são capazes, muito acima do "homem médio", atemorizando a família e a sociedade, quando } \\
\text { se embrenham nos descaminhos da margina1idade, e, por esse efeito, não devem ficar sob a tutela da legislação especial [grifo nosso]. }\end{array}$ \\
\hline
\end{tabular}

PEC 633/1999 As dúvidas se tomaram mais graves depois de promulgado o Estatuto do Menor e do Adolescente. Lei 8.069 de 13 de julho de 1990. Além de frequentes problemas com essa faixa etária também tem havido hesitação quanto ao tratamento disciplinar e de treinamento para o trabalho quando se tratam de menores de 14 ate os dezesseis anos [grifo nosso].

PEC 377/2001 Pensam que as medidas chamadas socioeducativas contidas no Estatuto da Criança e do Adolescente (Lei $n^{\circ} 8.069$, de 13 de julho de 1990$)$ entre as quais a internação, que corresponde à privação de liberdade - não molestarão e em breve ver-se-ão livres de qualquer punição.

PEC 582/2002 Neste ano 2002, os infratores e responsáveis por condutas antissociais com idade inferior a 18 anos estão sujeitos ao Estatuto da Criança e Adolescência.

Desconhece-se, em verdade, a realidade biológica, social e jurídica atuais, pois os adolescentes ascenderam, durante o passar desses vividos 86 anos, a pauta dos direitos e obrigações, inerentes à cidadania.

PEC 242/2004 Temos que admitir que as medidas socioeducativas do Estatuto da Criança e do Adolescente (Lei $n^{\circ}$ 8.069/90) não têm sido eficientes como se esperava (...).

PEC 48/2007 Mas, essas normas pragmáticas [vida, educação, lazer etc.] , mesmo após a edição do ECA - Estatuto da Criança e do Adolescente - ficaram praticamente no papel.

PEC 399/2009 Frente às adversidades legais encontradas e ainda por ser o tema "adolescente infrator" extremamente complexo e carregado de emoções, as medidas especiais, socioeducativas, discriminadas pelo Estatuto da Criança e do Adolescente são as menos implementadas em nosso sistema carcerário de forma satisfatória [grifo nosso].

Essa Proposta de Emenda à Constituição está focada no cerne do problema; dada a inviabilidade, frente a quase duas décadas de existência, de efetivo cumprimento das medidas e disposições socioeducativas do ECA.

Analisemos agora a mão de obra adolescente empregada unicamente no tráfico. A criminalidade faz uso de mão-de-obra jovem porque confia no Estatuto da Criança e do Adolescente minorando as penas cominadas.

PEC 228/2012 [Os adolescentes] sabem o quão são brandas as medidas que lhe são impelidas.

PEC 279/2013 Em sua avaliação, o modelo atual, previsto pelo Estatuto da Criança e do Adolescente (ECA), que determina a aplicação de medidas socioeducativas a jovens que praticam atos infracionais, leva a uma situação de "verdadeira impunidade".

"Em grande parte dos crimes, quem o comete vai responder em meio aberto ou com liberdade assistida, sendo acompanhado por um assistente social, e ainda ter direito de participar de cursos profissionalizantes, configurando até uma espécie de favor que o Estado lhe presta", disse [um promotor da Vara da Infância e da Juventude] [grifo nosso].

PEC 332/2013 (...) é cediço que as medidas socioeducativas não atendem a finalidade da pena, pois além de não se coadunarem com as exigências de justiça, não têm o condão de inibir a prática de novas infrações.

Fonte: Autoras 


\section{Realidade Social e Psicológica como Contraponto ao Critério Cronológico}

Uma questão relevante nas PECs analisadas diz respeito ao questionamento da idade biológica como critério de fixação da idade penal. A PEC 386/1996, por exemplo, aponta que a irresponsabilização penal indiscriminada desconhece um dado, que ela designa como incontestável, sobre a capacidade biopsíquica, psicológica e social de que os jovens abaixo de dezoito anos já são dotados para se determinarem e agirem, segundo seu entendimento e juízo de valor sobre o que é certo e errado, tendo consciência de suas ações.

De acordo com Vicentin (2006), a atribuição de responsabilidade aos jovens, quando se trata de autoria de ato infracional, assume relevância porque coloca em discussão inúmeras questões: tutela versus autonomia, direitos civis versus direitos sociais, justiça penal versus sistema socioeducativo. O tema da responsabilização/ irresponsabilização penal de jovens articula-se com a argumentação sobre a capacidade psíquica ou psicossocial tendo como objetivo demandar maior rigor na aplicação de medidas de segurança. A partir do que essa autora discute, é possível afirmar que essa questão de atribuição de responsabilização geralmente associa-se à noção de periculosidade dos sujeitos, já que as avaliações psiquiátricas e psicológicas têm como objetivo detectar possíveis transtornos de personalidade, como, por exemplo, o transtorno de personalidade antissocial. Em suma, a consideração do indivíduo ao nível de suas virtualidades e não de seus atos (Foucault, 1973/2003). Assim, ela aponta a periculosidade como uma noção que adquire contornos jurídicos mais do que clínicos.

É a partir do debate sobre uma necessidade de atribuir responsabilidade penal aos jovens abaixo de 18 anos que os proponentes da PEC 73/2007, por exemplo, defendem a diminuição da idade penal com base na avaliação médica e psicológica que determinará a capacidade de entendimento e maturidade do sujeito diante de um ato infracional, criando, dessa forma, a possibilidade de quaisquer jovens com idade abaixo de 18 anos cumprirem pena no sistema prisional comum, atualmente voltado aos adultos. Nesse sentido, argumentam que

O Código Penal, onde prepondera com mais vigor aspectos psicológicos, emocionais e de conhecimento do agente, deve sofrer alteração assemelhada. Não pela simples redução da menoridade penal, mas, pela avaliação de seus elementos subjetivos, conforme proposta na alteração. Abandona-se assim o critério cronológico para se adotar o critério subjetivo-psicológico (Brasil, PEC 73/2007, não paginado).

De forma semelhante, a PEC 87/2007 aponta para uma fragilidade do parâmetro biológico, o qual, de acordo com os legisladores que a propuseram, desconsidera os diferentes estágios de desenvolvimento psicológico e social dos indivíduos. A PEC 127/2007, por sua vez, critica contundentemente a Constituição Federal, ao afirmar que o artigo 228 - que estabelece a inimputabilidade penal dos menores de 18 anos - não considera as condições sociais, culturais e psicológicas dos adolescentes e nem os atos ilícitos por eles praticados, adotando puramente o critério cronológico para impor uma inimputabilidade a esses sujeitos.

Ao se passar do critério cronológico para o critério subjetivo-psicológico, a avaliação desses sujeitos incidiria sobre uma série de aspectos referentes a sua biografia individual, extrapolando as circunstâncias dos atos praticados. Dessa maneira, propor uma avaliação dos elementos subjetivos é possibilitar o esquadrinhamento das virtualidades do sujeito, debruçar-se sobre sua história de vida familiar, sobre seu comportamento, a constituição de sua personalidade e possíveis indicativos de uma periculosidade intrínseca a ele. Trata-se, portanto, de ampliar o poder de captura do judiciário sobre sua vida, amparado por todos os saberes psi que darão suporte e legitimarão decisões sobre a punição a ser aplicada. Esse critério subjetivo-psicológico sinaliza o que Foucault (1978-1979/2008) apontou como sendo uma substituição da mecânica da lei por uma antropologia do crime. O autor discute como, a partir de uma racionalidade de mercado aplicada como princípio de inteligibilidade para as relações sociais, o homo penalis (o sujeito que é penalizável mediante a lei) passa a ser cada vez mais tido como homo criminalis, através de uma tendência a uma modulação cada vez mais individualizante da aplicação da lei e, por conseguinte, reciprocamente, a uma problematização psicológica, sociológica, antropológica daquele a quem se aplica a lei. $\mathrm{Ou}$ seja, o homo penalis está derivando, ao longo de todo o século XIX, para o que se poderia chamar de homo criminalis (Foucault, 1978-1979/2008, p. 342).

Moreira e Toneli (2014) analisaram, a partir da arqueologia foucaultiana, documentos de jurisprudência arquivados nos Tribunais de Justiça da região Sul do país, procurando discutir as relações entre paternidade, família e criminalidade. A partir da articulação de enunciações que associam família e criminalidade, a autora destaca a noção de dosimetria na análise dos materiais 
pesquisados. A noção de dosimetria refere-se ao cálculo da pena no Direito, levando-se em conta a conduta do réu, sua personalidade, os antecedentes, os motivos e circunstâncias do crime, dentre outros fatores.

A noção de dosimetria discutida por Moreira e Toneli (2014) aproxima-se do que as propostas em discussão aqui denominam de critério subjetivo-psicológico, capacidade biopsíquica ou ainda realidade social e psicológica dos sujeitos. Enuncia-se uma demanda por avaliações minuciosas que considerem as circunstâncias em que o sujeito praticou determinado ato e não apenas a materialidade do ato em si. Ressalte-se que, nesse sentido, levar em conta o contexto dos sujeitos não quer dizer potencializar ou valorizar suas singularidades, mas efetuar uma análise caso a caso, a fim de extrair dos sujeitos o grau de periculosidade e buscar na família a gênese dos comportamentos criminosos. Dessa maneira, a análise do contexto social e da realidade em que se produzem as subjetividades facilmente é cooptada no discurso das PECs em questão, tornando-se uma espécie de armadilha diante da vontade punitiva que busca abarcar todas as virtualidades possíveis dos sujeitos, incidindo ao nível de seus comportamentos e atitudes (Foucault, 1973/2003). Portanto, quando as PECs enunciam e defendem a necessidade de se levar em conta a realidade psicossocial dos sujeitos, elas visam a torná-los cada vez mais penalizáveis.

\section{Sujeitos de Quais Direitos?}

Uma das mais importantes mudanças operadas pelo ECA é a concepção de crianças e adolescentes como sujeitos de direitos. Tensionando esse aspecto, colocam-se em questão, nos documentos que analisamos, os direitos garantidos pela Constituição e o fato de que a idade penal fixada aos 18 anos é tomada como cláusula pétrea, o que tem produzido alguns embates argumentativos (Alves, Pedroza, Pinho, Presotti, \& Silva, 2009).

A PEC 179/2003 interroga como é aceitável que um jovem de 16 anos possa escolher uma profissão, prestar vestibular, participar das escolhas políticas do país, cursar uma faculdade e, no entanto, não seja responsabilizado penalmente.Como disse o professor Fernando Whitaker, em sua obra "O Sistema Constitucional Brasileiro", a norma do artigo 228 da Constituição Federal encerra verdadeira contradição em seu bojo, pois considera inimputáveis os menores de 18 anos, que, nada obstante, em outra norma (art. $\left.14, \S 1^{\circ}, \mathrm{II}, \mathrm{c}\right)$, são admitidos a votar, o que nos leva a admitir, como lembrou o emérito constitucionalista, que "é evidente que, se estão habilitados a decidir o destino da pátria, deveriam responder pelos próprios atos, sob pena de gravíssimas consequências" (Brasil, PEC 48/2007, não paginado).

De modo semelhante, a PEC 223/2012 também indaga: "se uma pessoa menor de 18 (dezoito) anos pode trabalhar, contratar, casar e votar, por que não pode responder criminalmente?" (Brasil, PEC 223/2012, não paginado).

Assim, convoca-se nesse jogo de forças a produção de uma outra verdade sobre esses jovens: além de serem capazes de discernimento e entendimento sobre os atos infracionais que possam praticar, eles são capazes de dirigir veículos, administrar patrimônio, casar-se etc. Nesse sentido, os direitos civis vão sendo tomados como balizadores da responsabilização dos sujeitos jovens no que extrapola a esfera da vida civil, tornando-os mais penalizáveis. Dito de outro modo, através do reconhecimento de direitos civis que supostamente conferem uma certa autonomia aos sujeitos, sustenta-se também que eles devem ser responsabilizados penalmente.

É importante assinalar o modo como os direitos conquistados civilmente passam a ser tomados como legitimadores da racionalidade punitiva sobre os jovens. Ao mesmo tempo em que os direitos civis são entendidos como reveladores de uma maturidade, os direitos sociais praticamente não são mencionados nessas propostas. Essa pauta dos direitos evidencia que, a partir de uma certa produção sobre o que são direitos desses jovens, torna-se possível abdicar daquilo que está previsto no ECA. Nesse sentido, as propostas analisadas deixam entrever que certos direitos sociais não são considerados como tais, ou seja, não são reconhecidos/ legitimados por setores da sociedade, apesar de formulados legalmente.

Afirmamos que os direitos sociais são negligenciados nesses discursos porque se fala em responsabilização penal e se pede que os jovens respondam criminalmente por seus atos, desconsiderando-se que o próprio ECA prevê tal responsabilização, uma vez que as medidas socioeducativas possuem caráter educativo e sancionatório (Brasil, 2005; Francischini \& Campos, 2005). Além disso, o acesso às políticas públicas de saúde, educação, moradia, emprego, dentre outras, não é problematizado nessas propostas como um elemento constituinte do debate sobre políticas para a juventude. Fala-se somente que o Estado precisa garantir segurança à população atemorizada por esses jovens, 
mas não que esse mesmo Estado é também responsável pela promoção de outras políticas públicas. Aliás, em nome da segurança certos direitos podem ser suspensos legitimamente pelo Estado.

Nesse contexto, questionamo-nos: a negação de direitos sociais corresponde a um processo de exclusão desses sujeitos? Como falar em exclusão se eles são cada vez mais tidos como alvo de ações do Estado, investidos por uma lógica punitiva e cerceadora de suas vidas e condutas?

Há uma clara diferenciação entre os que podem ter acesso aos direitos garantidos legalmente e aqueles que não devem ser considerados como sujeitos de direitos. Não afirmamos que se trate, contudo, de um mero processo de exclusão, uma vez que esses jovens devem ser captados por instituições que darão conta de puni-los, bem como por saberes e profissionais responsáveis por modular suas condutas. O que se produz, a nosso ver, é uma relação mais complexa, que Castel (2011) denomina de discriminação negativa ${ }^{3}$ : igualdade de direitos perante a lei, mas todo um sistema de diferenciações e associação a um destino embasado em características que marcam os sujeitos como uma espécie de estigma. Ainda que os direitos sociais estejam previstos em lei, há uma série de desqualificações que colocam esses jovens como indignos de direitos. A discriminação negativa não implica exclusão - se esta for entendida como banimento ou ausência de intervenção do Estado -, mas, em contrapartida, acentua a desigualdade e a periculosidade como marca desses jovens. Exemplo disso é o modo como as políticas públicas de segurança no Brasil tomam como alvo cada vez mais os jovens pobres e negros, que se constituem como alvo do maior número de encarceramentos e como vítimas da maior parte dos homicídios praticados no Brasil (Batista, 2009; Waiselfisz, 2014), a partir de processos discriminatórios que incidem sobre a população jovem, pobre e negra. A violência contra a juventude negra tornou-se um problema de Estado que se tem buscado gerenciar a partir de estratégias de governo como o Plano Juventude Viva, criado pelo governo federal em 2013 para implementar ações de enfrentamento à violência principalmente nas periferias brasileiras, onde residem jovens em situação de maior vulnerabilidade social (Waiselfisz, 2014).

No que se refere aos princípios da Constituição, a PEC 179/2003 coloca em questão o que se concebe como direitos fundamentais. Afirma que a idade em que se estabelece a imputabilidade penal não diz respeito às garantias fundamentais dos cidadãos, uma vez que imutável e fundamental é somente a estrutura do Estado Democrático, com a autonomia e independência dos Poderes Legislativo, Executivo e Judiciário. Assim, fixar a idade penal em uma determinada idade adquire status de norma constitucional somente em razão da vontade do legislador constituinte e não por constituir-se como uma cláusula pétrea.

Um dos efeitos desse discurso é individualizar o que se estabelece como constitucional ou não, no sentido de atribuir a um legislador o poder de decisão sobre os direitos e deveres que devem figurar na Carta Magna brasileira, como se o processo constituinte fosse abstrato e não resultante de articulações políticas e discussões coletivas de amplos setores da sociedade.

Assim, no entendimento do ilustre jurista [Reale], o art. 228 da Constituição da República NÃO É uma norma pétrea, isto é, um direito e uma garantia individual que se afigure como um princípio fundamental para a manutenção da estabilidade e da Ordem Constitucional e a preservação do Estado Democrático de Direito, razão pela qual a questão da maioridade penal pode ser arguida e modificada, uma vez que as legislações devem acompanhar a evolução social, se adequando as mudanças constantes que a sociedade sofre (Brasil, PEC 273/2013, não paginado) [destaques em letras maiúsculas no original].

Essa proposta menciona diversas citações de juristas no sentido de argumentar que o artigo 228 da Constituição não deve ser entendido como cláusula pétrea e que não se pode concordar com a tese de que haja direitos e garantias fundamentais para além do artigo $5^{\circ}$. Dessa maneira, os legisladores sustentam que não se pode impedir que gerações posteriores à do período histórico em que se elaborou a Constituição pautem suas condutas por normas que correspondem aos anseios e necessidades atuais da sociedade.

Manter a discussão em torno do que seriam direitos fundamentais dos sujeitos ou ainda do que pode ser considerado cláusula pétrea na Constituição torna o debate sobre uma possível redução da idade penal no Brasil improdutivo, uma vez que, ao desconsiderarem os direitos sociais dos jovens autores de atos infracionais, as PECs analisadas explicitam que tais direitos podem ser radicalmente modificados diante da demanda crescente por segurança e mais severidade nas punições para esses jovens. Se não há direitos universais, e sim direitos que são efeitos de lutas históricas e jogos de força, é razoável pensar que não podemos sustentar a discussão sobre uma possível redução da idade penal 
tomando certos direitos como fundamentais ou inerentes ao humano.

Do ponto de vista do Direito Constitucional, uma cláusula pétrea não é, necessariamente, considerada irreversível ou perpétua. Embora cláusulas pétreas sejam, por definição, aquelas tidas como imodificáveis ou irremovíveis da Constituição Federal, Santana (1993) afirma uma inutilidade das cláusulas pétreas, argumentando que se constituem como obstáculo aos processos de reforma constitucional e que, na prática, elas não são imodificáveis, pois, dependendo de um conjunto de forças que emergem da própria sociedade, o que se considera como imutável deixa de ser válido diante de determinada conjuntura política. Endossando esse argumento, Martins (2003) aponta que "as cláusulas pétreas seguem, na prática, o mesmo regime de mutação das cláusulas ordinárias de uma Constituição, apenas sendo mais sofisticados os caminhos para sua alteração, via jurisprudência, quando não decorrentes de ruptura institucional" (p. 183). O autor afirma ainda que na Comissão de Constituição e Justiça da Câmara dos Deputados os acordos políticos prevalecem sobre os aspectos jurídicos. Além disso, de um ponto de vista genealógico, Foucault nos alertou que as coisas não têm em si mesmas uma essência e que se quisermos afirmar que há uma essência nelas precisaremos admitir que essa 'essência' é construída peça por peça (Foucault, 1979).

Nesse sentido, há mais potencialidade, a nosso ver, em problematizar os direitos sociais na área de proteção à infância e juventude justamente como conquistas sociais. Trata-se, nesse caso, de refletirmos sobre a possibilidade de se desconsiderar, a partir das PECs que analisamos, certos processos históricos de conquistas de direitos. É possível simplesmente elidir do debate as lutas coletivas e sociais que possibilitaram a promulgação do ECA, em nome de uma suposta proteção à sociedade? De qual projeto de sociedade se fala quando se formula um conjunto de propostas 'em defesa da sociedade' que, no entanto, se contrapõe a inúmeras conquistas históricas, coletivas e sociais?

\section{Ineficácia das Práticas Pautadas no Estatuto da Criança e do Adolescente}

Além de questionarem o critério cronológico utilizado para fixação da idade penal e os direitos sociais, as propostas analisadas também tensionam o ECA no tocante às práticas produzidas a partir dele, especialmente as PECs propostas a partir da década de 2000; portanto, as mais recentes.
A PEC 133/1999 argumenta que o ECA, mesmo prevendo a internação como uma medida socioeducativa, não tem se mostrado eficaz para a redução da violência. Em conformidade com essa ideia, a PEC 242/2004 também sustenta que as medidas socioeducativas não têm sido eficientes.

A PEC 48/2007 defende que a Constituição Federal de 1988, em seu art. 227, teve o cuidado de declarar que a criança e o adolescente são titulares de direitos fundamentais, como à vida, educação, lazer, profissionalização, dignidade, respeito, convivência familiar, entre outros. Mas, essas normas pragmáticas, mesmo após a edição do ECA - Estatuto da Criança e do Adolescente - ficaram praticamente no papel. Faltam iniciativas governamentais, capazes de garantir aos menores abandonados, abrigo - que não se pareça com os "depósitos" hoje existentes, verdadeiras escolas de criminalidade - e, aos menores delinquentes ${ }^{4}$, estabelecimentos capazes de conduzi-los à ressocialização, através de estudo, de trabalho e da profissionalização (Brasil, PEC 48/2007, não paginado).

Cabe apontar que, apesar do reconhecimento de que faltam iniciativas governamentais na formulação de políticas públicas para o segmento juvenil - ainda que essa preocupação esteja claramente associada à ideia de risco que esses 'menores' representam para a sociedade, especialmente por serem improdutivos economicamente -, o que se defende não é a produção dessas políticas no sentido de atender aos direitos que 'praticamente ficaram no papel', mas sim que esses jovens possam ser penalizados mais cedo com base no Código Penal. Uma vez afirmada a ineficácia do sistema socioeducativo, também não se coloca em discussão quais seriam os aspectos do sistema prisional do país que se diferenciariam do sistema socioeducativo, no sentido de produzir a almejada eficiência.

Um trecho que merece destaque na Tabela 1 é o que afirma que "as medidas especiais, sócio-educativas, discriminadas pelo Estatuto da Criança e do Adolescente são as menos implementadas em nosso sistema carcerário de forma satisfatória" (Brasil, PEC 399/2009, p. 02) [grifo nosso]. Mais do que tomar essa afirmação como um equívoco ou absurdo, é preciso tomá-la como elemento crítico da realidade, visto que essa enunciação apoia-se em uma série de práticas que fazem ver o carcerário onde o ECA preconiza o socioeducativo. Dito de outro modo, a condição de possibilidade para tal afirmação não é um mero engano, mas reside na inscrição de certas práticas no real, configurando rotinas, normas 
e concepções que institucionalizam a cultura carcerária no sistema socioeducativo.

Discutimos anteriormente o modo como os direitos sociais são negados, a partir do reconhecimento dos direitos civis tomados como indicadores de que os jovens abaixo de dezoito anos possuem maturidade o suficiente para responder penalmente por seus atos. Nesse contexto em que o debate sobre a cidadania reduz-se ao núcleo duro dos direitos civis (L. A. M. Silva, Leite, \& Fridman, 2005), afirma-se que "em grande parte dos crimes, quem o comete vai responder em meio aberto ou com liberdade assistida, sendo acompanhado por um assistente social, e ainda ter direito de participar de cursos profissionalizantes, configurando até uma espécie de favor que o Estado Ihe presta", disse [um promotor da Vara da Infância e da Juventude] (Brasil, PEC 279/2013, p. 03). Delineia-se aqui um dos paradoxos das democracias neoliberais: o Estado passa a pensar as políticas públicas a partir de uma racionalidade fundamentada no homo oeconomicus (Foucault, 1978-1979/2008), agindo sob a lógica dos interesses e a partir de uma razão governamental centrada na maximização da economia, mesmo quando os aparatos jurídicos garantem investimentos estatais para um sujeito de direitos.

De acordo com Gonçalves e Garcia (2007), a partir da concepção de crianças e jovens como sujeitos de direitos, a provisão de serviços deixa de estar calcada no favor, no medo e na pena. No entanto, a sociedade e o Estado que deveriam prover os recursos para que crianças e jovens consolidem-se como sujeitos de direitos estão cada vez mais ausentes da vida coletiva. Assim, ainda de acordo com as autoras, a realidade dos serviços públicos, a despeito do que preveem os documentos legislativos, mostra um quadro de escassez, sobretudo nos territórios empobrecidos do país.

No que diz respeito aos jovens autores de atos infracionais, ainda tidos como menores em se tratando do reconhecimento social a eles dispensado, Gonçalves e Garcia (2007) afirmam que o problema, além da provisão de serviços, estende-se às práticas criminalizantes, subsidiadas por uma cultura que exige para esses jovens o afastamento do convívio social. As autoras criticam a maneira como as políticas públicas vêm sendo efetivadas de modo a conceber o pobre como sinônimo de ameaça e de incômodo e reproduzindo estigmas atrelados à condição de pobreza, a partir da articulação da tríade menoridade-pobreza-perigo.

As críticas elaboradas com relação ao ECA vão apontando que, apesar de duas décadas e meia de existência, o efetivo cumprimento de suas medidas e disposições ainda parece distante de ser concretizado. O que chamam a nossa atenção nas PECs não são as críticas ao Estatuto, mas o modo como elas servem de justificativa para a precarização da vida e a produção de práticas de morte contra jovens, entendidas conforme Foucault (1975-1976/1999) nos aponta: não somente a morte física, mas também tudo o que indiretamente multiplica o risco de morte e produz abandono social.

As desqualificações enunciadas nos documentos analisados não são formuladas no sentido de propor uma revisão do ECA nem de repensar melhorias para o sistema socioeducativo, tampouco para o sistema prisional do país, tais como a reestruturação de espaços físicos adequados e práticas de rompimento com a cultura da cadeia, priorizando práticas como a justiça restaurativa, por exemplo. Além disso, não se trata de críticas formuladas no sentido de ampliar a efetivação de políticas sociais, mas tão somente de instrumentalizar o recrudescimento punitivo.

\section{Considerações finais}

Empreendemos aqui uma análise sobre como o Estatuto da Criança e do Adolescente passa a ser tensionado nas PECs que propõem a redução da idade penal no Brasil. Passa-se do critério cronológico ao subjetivo-psicológico e vai-se delineando uma dosimetria da pena, voltada a aspectos como os antecedentes do sujeito, histórico familiar, comportamento etc. Apontamos que esse esquadrinhamento das virtualidades do sujeito, operado por uma série de saberes e poderes laterais, à margem da justiça, como os saberes psi, por exemplo, ampliam o poder de captura do judiciário sobre sua vida.

Discutimos também o modo como os direitos civis vão sendo tomados como balizadores de uma responsabilização dos sujeitos jovens que extrapola a esfera da vida civil, tornando-os mais penalizáveis, na medida em que, a partir do discurso da responsabilidade e da consciência, faz com que se fale no endurecimento penal diante do atual Código Penal. Em contrapartida, há uma negação dos direitos sociais para jovens autores de atos infracionais. Eles não são tidos como sujeitos para os quais o Estado deva garantir os direitos destinados aos cidadãos 'comuns', pois mesmo quando são entendidos como alvo de proteção concebe-se que isso ocorra pela via da punição. 
O Estatuto da Criança e do Adolescente é objetivado nas propostas analisadas como ficção legal, que não possibilita punir com o devido rigor e acaba acobertando, incentivando e garantindo a continuidade da 'criminalidade' juvenil. A ideia de que o ECA é uma legislação paternalista, através da qual o Estado se vê obrigado a prestar favores oferecendo cursos profissionalizantes a jovens na condição de autores de ato infracional, denota o quanto a concepção menorista ainda permeia as políticas e práticas voltadas à infância e juventude, traduzida nessas noções de favor e paternalismo. Nesse sentido, as críticas sobre a ineficácia do ECA e sua não efetivação servem mais a uma precarização da vida dos sujeitos do que à melhoria das atuais políticas de segurança e assistência social. Também não se trata de críticas formuladas no sentido de ampliar a efetivação de políticas sociais, mas tão somente de instrumentalizar o recrudescimento punitivo. Desse modo, a proposição dessas PECs é também uma forma de violência, sobretudo considerando-se as inúmeras reivindicações de diversos movimentos populares/ sociais em prol da garantia de direitos para a população infanto-juvenil.

Foucault (1970/2012b) nos apontou que os discursos não apenas traduzem lutas ou sistemas de dominação, mas são aquilo pelo qual se luta, constituindo-se como alvo de disputas. Não são mera representação ou tradução do mundo ancorada em um sujeito fundante, mas uma produção social sustentada em uma rede de relações estratégicas. É à função estratégica dos discursos que buscamos dar visibilidade ao discutirmos as desqualificações do ECA nas propostas de redução da idade penal. Ao desqualificarem o ECA, as PECs têm uma positividade, isto é, uma produtividade que busca tornar possíveis certas práticas, relações e formas de governo sobre os sujeitos, calcadas naquilo que denominamos anteriormente de precarização da vida, produção de morte e abandono social. Além disso, cabe pensarmos na importância do debate sobre tais propostas especialmente no que concerne à atuação da Psicologia junto às políticas de segurança pública e de assistência social. Entendemos ser necessário situar este debate na Psicologia como uma questão do presente que nos convoca à construção permanente de práticas e produções de saberes que pautem-se no combate à lógica do encarceramento, em prol do compromisso ético-político com a conquista de direitos sociais e com a valorização dos jovens como autores de suas histórias de vida, capazes de construir trajetórias existenciais favoráveis à ressignificação e ruptura com atos infracionais. Cabe à Psicologia situar a violência em suas múltiplas determinações, colocando em diálogo a necessidade de superar mecanismos meramente coercitivos e punitivos e a criação de estratégias alternativas à reprodução da cultura carcerária defendida pelas propostas de redução da idade penal.

\section{Referências}

Alves, C., Pedroza, R., Pinho, A., Presotti, L., \& Silva F. (2009). Adolescência e maioridade penal: reflexões a partir da Psicologia e do Direito. Psicologia Política, 9(17), 67-83. Recuperado de http:// pepsic.bvsalud.org/pdf/rpp/v9n17/v9n17a05.pdf

Augusto, A. (2013). Política e polícia: cuidados, controles e penalizações de jovens. Rio de Janeiro: Lamparina.

Batista, V. M. (2009). A juventude na criminologia. In H. Bocayuva \& S. A. Nunes (Orgs.), Juventudes, subjetivações e violências (pp. 91-99). Rio de Janeiro: Contra Capa.

Castel, R. (2011). A discriminação negativa: cidadãos ou autóctones? ( $2^{\mathrm{a}}$ ed.). Petrópolis: Vozes.

Castro, E. (2009). Vocabulário de Foucault: um percurso pelos seus temas, conceitos e autores. Belo Horizonte: Autêntica.

Espíndula, D. H. P., \& Santos, M. F. S. (2004). Representações sobre a adolescência a partir da ótica dos educadores sociais de adolescentes em conflito com a lei. Psicologia em Estudo, 9(3), 357-367. doi: 10.1590/S1413-73722004000300004

Foucault, M. (1979). Microfísica do poder. São Paulo: Graal.

Foucault, M. (1999). Em defesa da sociedade: curso no Collège de France. São Paulo: Martins Fontes. (Obra original publicada em 1975-1976).

Foucault, M. (2003). A verdade e as formas jurídicas (3 $3^{\text {a }}$ ed.). Rio de Janeiro: Nau Editora. (Obra original publicada em 1973)

Foucault, M. (2008). Nascimento da biopolítica: curso no Collège de France. São Paulo: Martins Fontes. (Obra original publicada em 1978-1979).

Foucault, M. (2012a). A arqueologia do saber (8 $8^{\underline{a}}$ ed.). Rio de Janeiro: Forense Universitária. (Obra original publicada em 1969)

Foucault, M. (2012b). A ordem do discurso (22 a ed.). São Paulo: Edições Loyola. (Obra original publicada em 1970)

Francischini, R., \& Campos, H. R. (2005). Adolescente em conflito com a lei: limites e (im)possibilidades. Psico, 36(3), 267-273. Recuperado de http://revistaseletronicas.pucrs.br/ojs/index.php/ revistapsico/article/view/1397/1097

Gonçalves, H. S., \& Garcia, J. (2007). Juventude e sistema de direitos no Brasil. Psicologia: Ciência e Profissão, 27(3), 538-553. doi: 10.1590/S1414-98932007000300013

Lei $n^{\circ}$ 8.069, de 13 de julho de 1990 (1990, 13 de julho). Dispõe sobre o Estatuto da Criança e do Adolescente e dá outras providências. Brasília, DF: Presidência da República.

Mallart, F. (2014). Cadeias dominadas: a Fundação CASA, suas dinâmicas e as trajetórias de jovens internos. São Paulo: Terceiro Nome.

Martins, I. G. S. (2003). Das cláusulas pétreas. In A. R. Tavares, O. A. V. A. Ferreira, \& P. Lenza (Orgs.), Constituição Federal 15 anos: mutação e evolução - comentários e perspectivas (pp. 175-191). São Paulo: Editora Método. 
Moreira, L. E., \& Toneli, M. J. F. (2014). Paternidade, família e criminalidade: uma arqueologia entre o Direito e a Psicologia. Revista Psicologia \& Sociedade, 26(n. spe), 36-46. Recuperado de http:// www.ufrgs.br/seerpsicsoc/ojs2/index.php/seerpsicsoc/article/ view/3721/2341

Nascimento, M. L., \& Scheinvar, E. (2009). As tensões como potência na prática profissional. Psico, 40(2), 168-173. Recuperado de http://revistaseletronicas.pucrs.br/ojs/index.php/revistapsico/article/ view/4192/4529

PEC 14/1989 (1989). Altera o artigo 228 da Constituição Federal. Reduzindo para 16 anos de idade a imputabilidade da responsabilidade penal, alterando a constituição federal de 1988. Brasília, Câmara dos Deputados. Recuperado de http://www.camara.gov.br/ proposicoesWeb/fichadetramitacao? idProposicao $=169234$

PEC 171/1993 (1993). Altera a redação do art. 228 da Constituição Federal (imputabilidade penal do maior de dezesseis anos). Brasília, Câmara dos Deputados. Recuperado de http://www.camara.gov.br/ proposicoesWeb/fichadetramitacao?idProposicao $=14493$

PEC 386/1996 (1996). Modifica o art. 228 da Constituição Federal. Excetua da inimputabilidade penal os maiores de dezesseis e menores de dezoito anos no caso de crimes contra a pessoa, o patrimônio e dos crimes hediondos. Brasília, Câmara do Deputados. Recuperado de http://www.camara.gov.br/proposicoesWeb/ fichadetramitacao?idProposicao $=14747$

PEC 133/1999 (1999). Dá nova redação ao art. 228 da Constituição Federal, que trata da inimputabilidade penal. Declara inimputáveis os menores de dezesseis anos, sujeitos às normas da legislação especial. Brasília, Câmara dos Deputados. Recuperado de http://www.camara.gov.br/proposicoesWeb/ fichadetramitacao?idProposicao $=14436$

PEC 179/2003 (2003). Dá nova redação ao art. 228 da Constituição Federal. Estabelece que serão penalmente inimputáveis os menores de 16 (dezesseis) anos. Brasília, Câmara dos Deputados. Recuperado de http://www.camara.gov.br/proposicoesWeb/ fichadetramitacao?idProposicao $=136870$

PEC 242/2004 (2004). Dá nova redação ao artigo 228 da Constituição Federal. Declara inimputáveis os menores de quatorze anos. Brasília, Câmara dos Deputados. Recuperado de http://www.camara.gov.br/ proposicoesWeb/fichadetramitacao? idProposicao $=155005$

PEC 48/2007 (2007). Altera o art. 228 da Constituição Federal. Reduz a idade penal para 16 (dezesseis) anos, considerando os maiores de dezesseis anos imputáveis penalmente. Brasília, Câmara dos Deputados. Recuperado de http://www.camara.gov.br/ proposicoesWeb/fichadetramitacao? idProposicao $=348776$

PEC 73/2007 (2007). Dá nova redação ao art. 228 da Constituição Federal. Estabelece que a autoridade judiciária decidirá sobre a imputabilidade penal do menor de 18 (dezoito) anos. Brasília, Câmara dos Deputados. Recuperado de http://www.camara.gov. $\mathrm{br} /$ proposicoesWeb/fichadetramitacao idProposicao $=353719$

PEC 87/2007 (2007). Considera penalmente imputáveis os menores de dezoito anos nos casos que especifica. Brasília, Câmara dos Deputados. Recuperado de http://www.camara.gov.br/ proposicoesWeb/fichadetramitacao?idProposicao $=354956$
PEC 127/2007 (2007). Dá nova redação ao art. 166 da Constituição e seus $\S \S 1^{\circ}, 2^{\circ}$ e $7^{\circ}$ que dispõem sobre a tramitação dos projetos de lei relativos ao plano plurianual, às diretrizes orçamentárias, ao orçamento anual e aos créditos adicionais. Brasília, Câmara dos Deputados. Recuperado de http://www.camara.gov.br/ proposicoesWeb/fichadetramitacao?idProposicao=359971

PEC 399/2009 (2009). Dá nova redação ao art. 228 da Constituição Federal, tornando relativa a imputabilidade penal dos 14 aos 18 anos para crimes praticados com violência ou grave ameaça à integridade das pessoas. Brasília, Câmara dos Deputados. Recuperado de http://www.camara.gov.br/proposicoesWeb/ fichadetramitacao? idProposicao $=447034$

PEC 273/2013 (2013). Altera o art. 228 da Constituição da República, criando a Emancipação para Fins Penais. Brasília, Câmara dos Deputados. Recuperado de http://www.camara.gov.br/ proposicoesWeb/fichadetramitacao idProposicao $=579333$

PEC 279/2013 (2013). Dá nova redação ao art. 228 da Constituição Federal. Reduz para dezesseis anos a maioridade penal. Brasília, Câmara dos Deputados. Recuperado de http://www.camara.gov.br/ proposicoesWeb/fichadetramitacao?idProposicao $=581329$

Ponte. (2014). Na prática, SP já reduziu a maioridade penal, diz antropólogo. Recuperado de http://ponte.org/pesquisador-afirma-que-na-pratica-fundacao-casa-em-sp-ja-reduziu-maioridade-penal/

Rizzini, I. (2011). O século perdido: raízes históricas das políticas públicas para infância no Brasil ( $3^{\underline{a}}$ ed.). São Paulo: Cortez.

Santana, J. E. (1993). Revisão Constitucional - reforma e emendas. Belo Horizonte: Del Rey.

Santos, E. P. S. (2009). (Des)construindo a 'menoridade': uma análise crítica sobre o papel da Psicologia na produção da categoria "menor". In H. S. Gonçalves \& E. P. Brandão (Orgs.), Psicologia Jurídica no Brasil (pp. 205-248). Rio de Janeiro: Nau Editora.

Silva, A. K., \& Hüning, S. M. (2015). A racionalidade punitiva nas propostas de redução da idade penal brasileiras. Revista Subjetividades, 15(2), 245-256. Recuperado de http://pepsic.bvsalud.org/pdf/rs/ v15n2/08.pdf

Silva, L. A. M., Leite, M. P., \& Fridman, L. C. (2005). Matar, morrer, "civilizar": o "problema da segurança pública". Recuperado de http://www.ipardes.gov.br/pdf/cursos_eventos/governanca_2006/ gover_2006_01_matar_morrer_civilizar_luiz_silva.pdf

Vicentin, M. C. (2006). A questão da responsabilidade penal juvenil: notas para uma perspectiva ético-política. In ABMP, llanud, \& Secretaria Especial de Direitos Humanos (Orgs.), Justiça, adolescente e ato infracional: socioeducação e responsabilização (pp. 151-173). São Paulo: llanud.

Waiselfisz, J. J. (2014). Mapa da violência: homicídios e juventude no Brasil, 2014. Recuperado de http://juventude.gov.br/articles/participatorio/0009/4537/Mapa_da_violencia_2014-Amarelo.pdf

Yokoy, T., \& Oliveira, M. C. S. L. (2008). Trajetórias de desenvolvimento e contextos de subjetivação e institucionalização de adolescentes em cumprimento de medidas socioeducativas. Pesquisas e Práticas Psicossociais, 3(1), 85-95. Recuperado de http://www. ufsj.edu.br/portal2-repositorio/File/revistalapip/volume3_n1/pdf/ Yokoy_Oliveira.pdf 
1. Os termos 'menores delinquentes' vinculam-se à concepção menorista, pautada na Doutrina da Situação Irregular advinda do referido Código de Menores. O uso dessa expressão demarca ideais de controle, tutela e correção de sujeitos tidos como desviantes. Ressalte-se que tal expressão não constitui concepção teórico-conceitual adotada pelas autoras deste trabalho nem pelo atual Sistema de Garantia de Direitos da Criança e do Adolescente, posterior ao ECA.

2. "Analisador é um conceito empregado pela Análise Institucional que indica um acontecimento através do qual se decompõe uma totalidade, no sentido de produzir rupturas, de desnaturalizar as relações e perceber as redes de conexão de sentido constituintes dos modelos sociais" (Nascimento \& Scheinvar, 2009, p. 173). Entendemos analisador como algo que produz uma potência de problematização sobre certas racionalidades discursivas.

3. Castel desenvolve esse conceito para analisar as práticas de racismo e xenofobia em relação a jovens, filhos de imigrantes, habitantes das periferias francesas. Tomamo-lo neste contexto a fim de pensar que o conceito de exclusão não dá conta também do modo como os jovens autores de atos infracionais passam a ser cada vez mais alvo de certas ações. O estudo de Augusto (2013), por exemplo, discute o modo como eles são governados em espaços de controle a céu aberto, na execução de programas de medidas socioeducativas.

4. O uso das expressões menores abandonados e menores delinquentes diz respeito ao modo como as políticas voltadas à infância e à juventude ainda são atravessadas por concepções oriundas do Código de Menores de 1979, colocando em questão uma continuidade histórica entre as práticas operadas naquele momento e as práticas da atualidade, que deveriam romper com tais concepções a partir do ECA.

Aline Kelly da Silva, Mestre em Psicologia pela Universidade Federal de Alagoas (UFAL) com bolsa CAPES, é Professora do curso de Psicologia da Faculdade Pitágoras - Unidade Maceió/AL.

Endereço para correspondência: Rua Alfredo Lins Nascimento, n¹0, complemento E, Santa Lúcia, CEP: 57081-164, Maceió (AL).

Telefone: (82) 2126-5053.

E-mail: aline.ksilva@yahoo.com

Simone Maria Hüning, Doutora em Psicologia pela Pontifícia Universidade Católica do Rio Grande do Sul (PUCRS), Pós-doutora pelo Brazil Institute, King's College London (KCL), é Professora do Programa de Pós-Graduação em Psicologia da Universidade

Federal de Alagoas (UFAL). E-mail: simone.huning@ip.ufal.br 